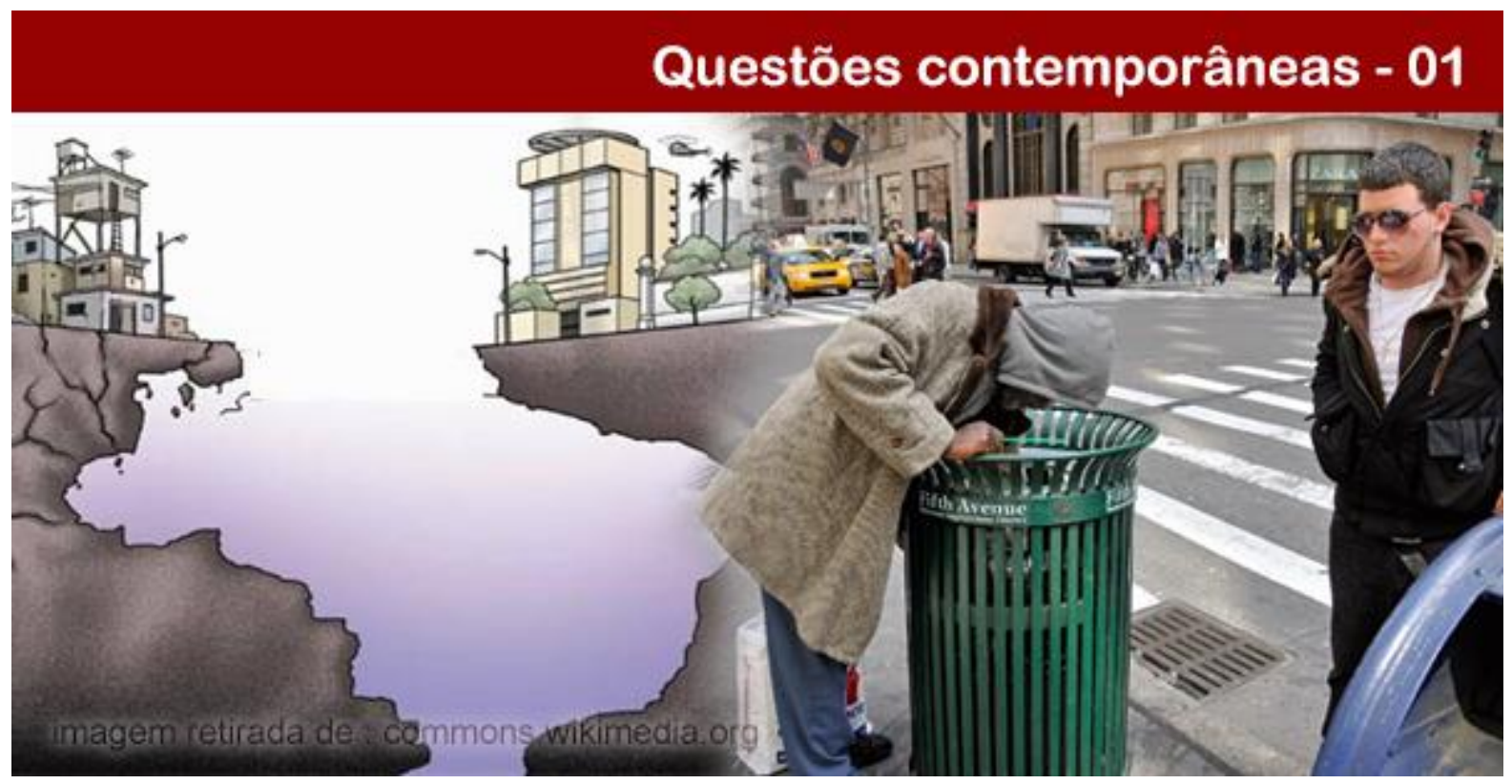

\title{
O SURVEY COMO DESENHO DE PESQUISA NA OBRA MOBILIDADE E DESIGUALDADE SOCIAL DE JOSÉ PASTORE
}

\section{Camila Perez da Silva}

Universidade Federal de São Carlos - UFSCar; Mestre em Sociologia e Doutoranda em Educação. E-mail: camilaperez25@gmail.com.

Resumo: Por ser a sociologia uma ciência empiricamente verificável, seus pesquisadores acionam diferentes desenhos de pesquisas e metodologias com vistas a atingir seus objetivos investigativos. O presente artigo tem por finalidade destacar aspectos centrais da aplicação de um tipo particular de pesquisa social denominado survey, na obra de José Pastore, Desigualdade e Mobilidade Social no Brasil. A produção de enunciados descritivos sobre uma determinada população obtidos por Pastore através deste desenho de pesquisa, possibilitou importantes descobertas acerca da distribuição de traços e atributos, permitindo realizar avaliações e asserções explicativas em virtude da generalização dos resultados obtidos. Foi a partir deste desenho de pesquisa, que o autor conseguiu apreender como se dá o complexo processo de estratificação social no Brasil, possibilitando assim, a compreensão detalhada sobre como realizar uma análise quantitativa e qualitativa acerca dos fenômenos estudados, especialmente quando a pesquisa abrange períodos muito amplos de tempo e espaço para sua efetivação. Por esse motivo, o estudo em questão tornou-se um clássico em termos da aplicabilidade desta metodologia em todo o país.

Palavras-chave: Survey. Desigualdade. Mobilidade Social.

\section{THE SURVEY AS A RESEARCH DESIGN IN SOCIAL WORK MOBILITY AND INEQUALITY JOSÉ PASTORE}

Resume: Being sociology an empirically verifiable science, its researchers trigger different research designs and methodologies in order to achieve their research goals. This article aims to highlight key aspects of the application of a particular type of social research called survey, in the work of José Pastore, Inequality and Social Mobility in Brazil. The production of descriptive statements about a population obtained by Pastore through this research design, enabled important discoveries on the distribution of traits and attributes, allowing carry out assessments and explanatory statements due generalization of the results obtained. It was from this research design, the author managed to grasp how is the complex process of social stratification in Brazil, thus enabling detailed understanding of how to conduct a quantitative and qualitative analysis about the phenomena

\section{POLÊM!CA | Revista Eletronica da Ueij}


studied, especially when the survey covers very ample periods of time and space for their enforcement. For this reason, the study in question has become a classic in terms of the applicability of this methodology throughout the country.

Keywords: Survey. Inequality. Social Mobility.

\section{Introdução}

Um dos desenhos de pesquisa frequentemente utilizados em diversas áreas do conhecimento, em especial nas Ciências Sociais, é o survey, em virtude da empregabilidade de técnicas específicas de investigação científica que têm por finalidade a descrição, explicação e/ou avaliação de determinadas fontes de eventos.

O presente artigo tem por finalidade abordar a utilização deste desenho de pesquisa no estudo realizado por José Pastore sobre o complexo processo de estratificação social no país. A obra intitulada Desigualdade e Mobilidade Social no Brasil configura-se em um importante exemplo da aplicação desta metodologia para futuros pesquisadores, pois possibilita a compreensão detalhada sobre como realizar uma análise quantitativa e qualitativa acerca dos fenômenos estudados, especialmente quando a pesquisa abrange períodos muito amplos de tempo e espaço para sua efetivação. E, embora tenha sido realizada com dados do PNAD (Pesquisa Nacional por Amostra Domiciliar realizada no Brasil) de 1973, ainda hoje representa um clássico exemplo de aplicação desta técnica.

\section{Caracterizações essenciais do survey}

De acordo com Babbie (2001) a "pesquisa de survey se refere a um tipo particular de pesquisa social empírica" (p. 65) que permite a produção de enunciados descritivos sobre determinada população, possibilitando ao pesquisador descobrir a distribuição de certos traços e atributos a fim de realizar asserções explicativas diversas. Assim, os "surveys podem diferir em termos de objetivos, custos, tempo e escopo" (p. 95) e são considerados desenhos de pesquisas amostrais, frequentemente empreendidos para entender aspectos de uma população maior do que a da amostra inicialmente selecionada, possibilitando a generalização dos resultados.

Há diversos tipos de survey: pesquisas demográficas; de opinião pública; de mercado sobre preferências do consumidor; estudos sobre preconceito; comportamento político, etc. As amostragens utilizadas neste modelo de pesquisa podem ser classificadas de diferentes formas: probabilística, não probabilística, aleatória simples, sistemática, estratificada, etc.

\section{POLÊM!CA | Revista Eletronica da Ueji}


Os surveys longitudinais permitem a análise de dados ao longo do tempo, e relatam mudanças de descrições e de explicações, analogamente às análises diacrônicas. Já os interseccionais, são utilizados quando os dados são colhidos num certo período de tempo, e a amostra selecionada serve para descrever alguma população maior numa mesma ocasião, similares às análises sincrônicas.

Os principais desenhos longitudinais são: estudos de tendências, no qual uma população pode ser amostrada e estudada em ocasiões diferentes, possibilitando a comparação de resultados de várias pesquisas e suas possíveis mudanças. Este tipo de survey se baseia em descrições de uma população geral ao longo tempo, ainda que os integrantes desta população mudem. Pois, como ressalta Babbie (2001) "pessoas vivas e representadas no primeiro estudo podem ter morrido por ocasião do segundo, e pessoas não nascidas, quando do primeiro estudo, podem estar representadas no segundo" (p.103). Há ainda os estudos de cortes, que focalizam a mesma população específica (ou seja, o mesmo perfil da amostra, a mesma coerência, mas não os mesmos respondentes) cada vez que os dados são coletados. Por exemplo, num momento, pode-se selecionar brasileiros entre 20 a 30 anos de idade para perguntar sobre o aborto. Dez anos mais tarde, a amostra será de pessoas dos 30 aos 40 anos. E os estudos de painel, que envolvem a coleta de dados ao longo do tempo, de uma mesma amostra de respondentes.

\section{Matrizes de transição e tipos de mobilidade utilizados por José Pastore}

O problema de pesquisa de Pastore exigia uma metodologia bastante eficaz que permitisse avaliar empiricamente o impacto dos fatores estruturais e individuais na mobilidade social, isolando os efeitos líquidos dessas variações tornando possível descobrir quais os mecanismos mais específicos da mobilidade social brasileira. Para realizá-la, o autor elegeu duas categorias centrais de análise: a desigualdade e a mobilidade social e, com o auxílio do survey, explicou a origem, a variação no tempo e no espaço e as consequências da estratificação social brasileira.

O autor utilizou modelos de regressão múltipla, com base em uma subamostra aleatória a partir dos dados de homens, chefes de família com idade entre 20 e 60 anos extraída da PNAD (Pesquisa Nacional de Amostra de Domicílios) e da Fundação IBGE (Instituto Brasileiro de Geografia e Estatística) do ano de 1973, que dividia o Brasil em oito

\section{POLÊM!CA | Revista Eletronica da Ueij}


regiões geoeconômicas: Brasília, Rio de Janeiro, São Paulo, Sul, Leste, Nordeste, Norte e Centro-Sul. Isso permitiu a utilização de um método de amostragem nacional probabilística durante todo o período de realização da pesquisa, qual seja, o quarto trimestre de 1973.

A pesquisa foi estruturada da seguinte maneira:

Figura - 1: Estrutura da pesquisa de José Pastore

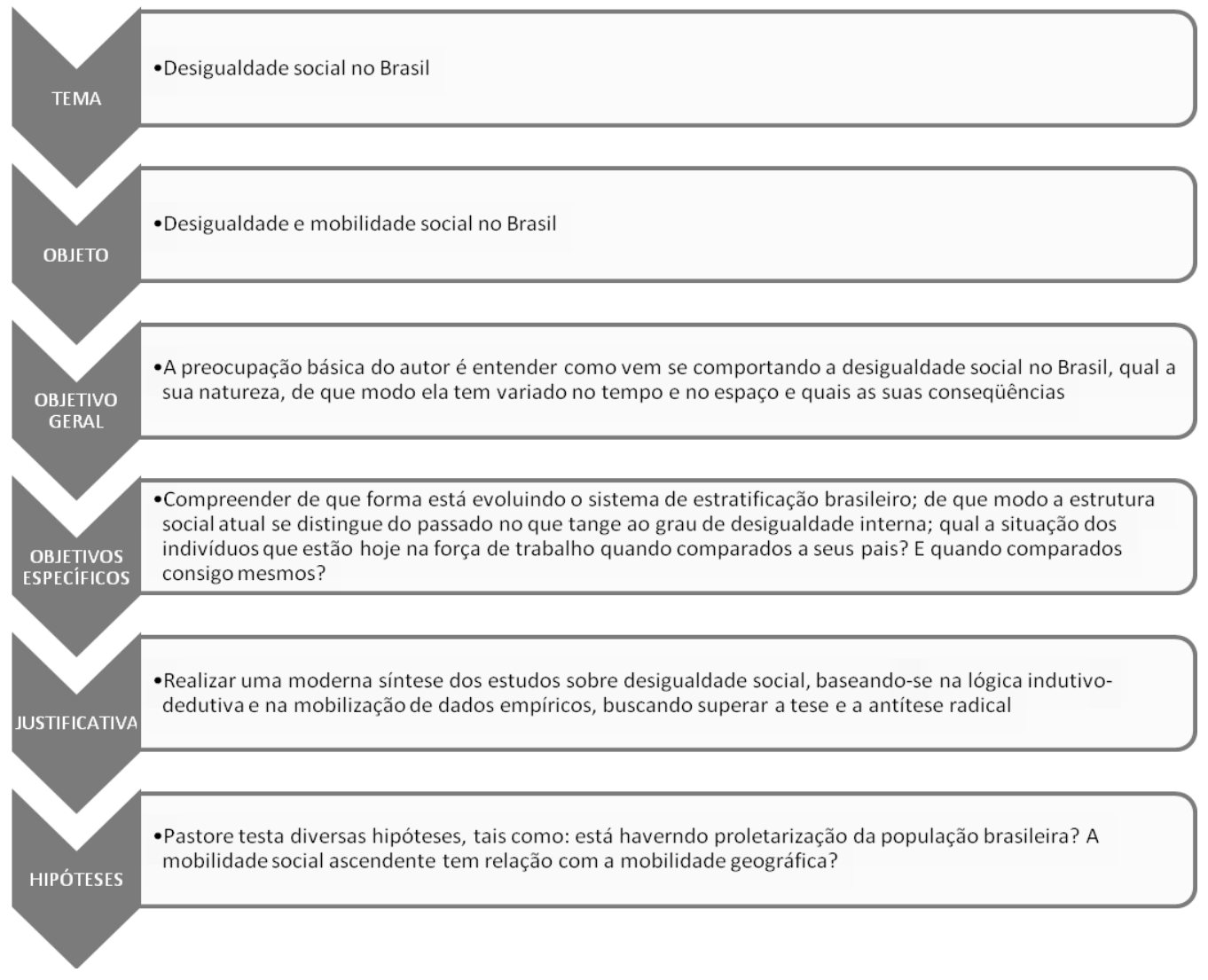

Fonte: A autora, 2015. Elaborada a partir da obra “Desigualdade e mobilidade social no Brasil”, 1979.

Pastore realizou uma aproximação metodológica ao survey longitudinal, empregando também alguns mecanismos do survey interseccional para aproximar o estudo de processo ou mudança em termos da mobilidade social no Brasil.

Dos 92.700 domicílios analisados pela Fundação IBGE, selecionou uma subamostra apenas de homens, chefes de família com idade entre 20 e 64 anos e sobre os quais se dispunha informações básicas relativas à ocupação do informante e de seu pai, que representaram 58.286 indivíduos. Destes, foram excluídos os indivíduos desempregados, os que apresentavam defeitos de resposta no item relativo à ocupação atual e os indivíduos cuja 
ocupação do pai apresentava imperfeições de resposta ou de codificação, o que resultou em uma amostra de $10 \%$ do total mencionado, ou seja, 5.820 indivíduos.

Após a seleção da amostra, um questionário foi aplicado às pessoas com 10 anos ou mais que moravam nos domicílios sorteados, com a finalidade de coletar dados sobre a ocupação atual do indivíduo; sua primeira ocupação e a ocupação de seu pai. As respostas obtidas foram codificadas de forma padronizada e registrada apenas quantitativamente num primeiro momento.

Em seguida, os registros padronizados foram submetidos a uma espécie de análise agregada para fornecer descrições dos trabalhadores pertencentes à amostra, com o intuito de determinar correlações entre diferentes respostas de forma qualitativa. As conclusões descritivas e explicativas obtidas por meio desta análise foram então generalizadas para a população da qual a amostra foi selecionada.

Seus estudos objetivavam identificar o volume e a direção do trânsito que os indivíduos realizam em relação a seus pais dentro da sua própria trajetória de vida, revelando o que ocorre com a estrutura social brasileira, a dinâmica social que envolve tal estrutura e o aproveitamento das oportunidades ocupacionais. Para tanto, o survey utilizado permitiu a produção de enunciados descritivos sobre a população, o que possibilitou a descoberta acerca da distribuição de certos traços e atributos, assim como a realização de asserções explicativas específicas sobre a população, o que exigiu uma análise multivariada, com o exame simultâneo de diversas variáveis.

Como variável dependente, o status ocupacional foi dividido em três categorias, numa escala que combinou ocupação, educação e renda, numa hierarquia de 259 títulos ocupacionais do Censo Demográfico de 1970: status ocupacional do pai; status ocupacional do indivíduo no início da carreira e status ocupacional atual (1973). Todavia, como o modelo de regressão apresentou falhas em relação às informações nas variáveis, o número de observações sofreu uma redução adicional. Desta forma, o autor utilizou também variáveis independentes, com base nas matrizes de transição de status: idade; educação formal; status ocupacional inicial; status paterno; região e migração.

A análise considerou a região de origem e o status migratório. Assim, a região permitiu apreender as diferenças sociais configurando-se em dados padrões de mobilidade

\section{POLÊM!CA | Revista Eletronica da Ueij}


diferentes. Já a migração, revelou que a mobilidade social está ligada à mobilidade geográfica, promovendo a ascensão tanto de migrantes como de não migrantes.

O controle etário também foi explorado pelo autor, uma vez que a mobilidade ocorre através do tempo e dos anos. Os indivíduos das amostras foram agrupados em 20-30 anos, 31-40 anos, 41-50 anos, 51-64 anos e tais agrupamentos, constituíram indicativos de diferentes pontos da carreira em diferentes momentos históricos do desenvolvimento brasileiro. Os dados foram tratados longitudinalmente podendo detectar as transformações ocorridas em várias décadas.

Segundo Pastore, os estudos que haviam sido desenvolvidos até 1973 no Brasil, sugeriam que a maioria da população ascende pouco, enquanto uma minoria ascende muito. Para verificar a legitimidade destas proposições, o autor estudou separadamente, as distâncias sociais desempenhadas por indivíduos de diferentes camadas sociais, tomando como foco, as classes baixas e médias, trabalhando a categorização dos status em 6 níveis: baixo-inferior, baixo-superior, médio-inferior, médio-médio, médio-superior e alto.

O termo "classe" foi utilizado neste estudo como referência ao conjunto formado pelos status ocupacionais. O autor verificou que os estratos baixo-inferior e baixo-superior contemplam ocupações de baixa qualificação, educação e renda e que a grande diferença entre esses dois estratos está em que o baixo-inferior possui um lócus rural maior, enquanto que o baixo-superior engloba um lócus urbano mais amplo. Esses dados tornaram possível a verificação de que a mobilidade intergeracional ascendente no país é maior do que a descendente e a imobilidade nesses dois estratos. Porém, quem já estava no ambiente urbano teve uma mobilidade maior em relação à população do ambiente rural.

As categorias centrais de análise foram: as de mobilidade total, mobilidade ascendente, mobilidade descendente, mobilidade estrutural, mobilidade vertical e mobilidade circular.

A mobilidade total, considerava a proporção de indivíduos que sobem e descem na estrutura social. Sob esta perspectiva, uma sociedade pode ser bastante flexível quando tende a colocar os indivíduos em status bem diferentes da origem. Rígida, portanto, seria a sociedade na qual os indivíduos tendem a permanecer no status de origem.

Já a mobilidade ascendente, dizia respeito aos indivíduos pertencetes a uma sociedade flexível em termos da ocupação de status hierarquicamente superiores aos de sua origem, 
enquanto que a mobilidade descendente, representa a categoria na qual os indivíduos de uma sociedade flexível ocupam status inferiores aos de sua origem.

Pastore ressalta ainda, que as vagas na sociedade são criadas pela geração de novos empregos ou pela saída dos indivíduos das posições existentes. Quando as vagas se tornam abundantes, a mobilidade ocorre independente da mobilidade dos indivíduos, constituindo o que ele denominou de modalidade estrutural.

Já quando as novas posições são escassas ou criadas lentamente, as características individuais tendem a aumentar de importância e passam a determinar a ocupação dessas poucas vagas abertas. Neste caso tem-se a mobilidade circular. A decomposição dessas últimas duas mobilidades permitiu estimar a proporção de cada uma delas e associá-las ao padrão de desenvolvimento da sociedade.

Essa classificação da mobilidade em diferentes categorias de análise permitiu que Pastore (1979) verificasse que "nascer na classe baixa urbana garante maior probabilidade de ascensão social quando comparada com a classe baixa rural" (p.149), e que, portanto, "nascer na classe baixa urbana parece proporcionar mais horizonte social do que nascer na classe baixa rural" (p. 150), chegando à constatação de que as perspectivas são muito maiores para as classes urbanas, devido ao maior número de possibilidades e oportunidades oferecidas nas grandes cidades.

Já nos dois estratos mais baixos (baixo-inferior/baixo-superior), os indivíduos apresentaram significativa mobilidade vertical, pois os filhos acabam ocupando posições mais elevadas que a dos pais; e que a mobilidade social nesses dois estratos está diretamente associada ao processo de migração do ambiente rural para o ambiente urbano. Ou seja, a maioria dos pais pesquisados no estrato baixo-inferior tinha ocupação rural, enquanto que grande parte de seus filhos migraram para ocupações urbanas. Para Pastore, essa migração representa um fator determinante em termos da ascensão social, de modo que aqueles que migraram, ascendem para ocupar a posição daqueles que já estavam lá e também ascendem para novas e mais altas posições/ocupações. A este tipo de mobilidade, o autor denominou de mobilidade circular.

As oportunidades que surgem na zona urbana, portanto, mesmo que precárias, são suficientes para ascender os oriundos da zona rural e promover uma grande mobilidade social na classe baixa.

\section{POLÊM!CA | Revista Eletronica da veri}


Já em termos da ascensão para os indivíduos de classe média a mobilidade se torna mais difícil, pois quanto maior a posição social, menor é o número de vagas. Isso ocorre porque o espaço de mobilidade social para esses indivíduos é muito mais limitado do que para os indivíduos do estrato baixo-inferior. Além do que, a partir desse nível aumentam as exigências de maior qualificação profissional, diminuindo as ocupações manuais.

A mobilidade do estrato médio-inferior foi de curta distância. Apesar desse fato, a classe média ascende mais que a classe baixa, tendo em vista sua maior limitação de mobilidade e as exigências mais rigorosas para a ascensão. Segundo Pastore (1979), "a classe média tem sido mais beneficiada em termos da distância percorrida, embora tenham sido poucos os que puderam usufruir disso" (p. 152).

No estrato médio-médio, foram bem poucos os que subiram, mas estes deram saltos muito grandes na mobilidade social. No estrato médio-superior, a possibilidade maior era de descendência, com uma maior probabilidade de descendência na escala social.

\section{Análise de Resultados}

Por meio do survey aplicado, Pastore demonstrou como os estudos sobre mobilidade no Brasil tornam possível a identificação do grau de fluidez e rigidez da estrutura social.

A análise da fluidez tem relação direta com o intenso dinamismo da sociedade brasileira e às inúmeras transformações ocorridas ao longo do século XX, que resultaram em marcantes repercussões em sua estrutura social. Dentre elas, o autor destaca: a expansão e consolidação do processo de industrialização que proporcionou não apenas o aumento das ocupações industriais, como também a expansão das ocupações periféricas (setor de serviços); a ampliação das atividades do comércio; a intensificação dos processos de urbanização e migração, em virtude da passagem de uma sociedade rural para a urbana. Tal passagem se constituiu no fenômeno de maior impacto para a estrutura social brasileira, uma vez que proporcionou o surgimento de uma classe média bastante razoável, aumentando substancialmente as ocupações para os chefes de família.

A terceirização dos mercados de trabalho resultou na feminilização da força de trabalho e no aumento expressivo do trabalho infantil. Todavia, apesar das desigualdades de oportunidades entre homens e mulheres e da intensa exploração da mão-de-obra infantil, a terceirização do mercado de trabalho proporcionou uma melhoria significativa em relação ao

\section{POLÊM!CA | Revista Eletronica da Ueij}


status ocupacional para os chefes de família, dado que, quanto mais mulheres e crianças nos postos de trabalho com status inferior, maiores as oportunidades para os chefes de família de ocuparem cargos com status mais elevado.

O autor ressalta ainda, que melhorando o status ocupacional dos chefes de família, ocorre uma melhoria expressiva em relação às oportunidades educacionais para seus filhos. A educação, portanto, era altamente determinada pelo status do pai, sugerindo que o impacto do status do pai na determinação do status do filho não se processa diretamente, mas indiretamente, via educação e outras variáveis, como o status inicial, por exemplo. Tal movimento pode ser representado através do esquema a seguir:

Figura - 2: A influência da educação na mobilidade do status dos filhos

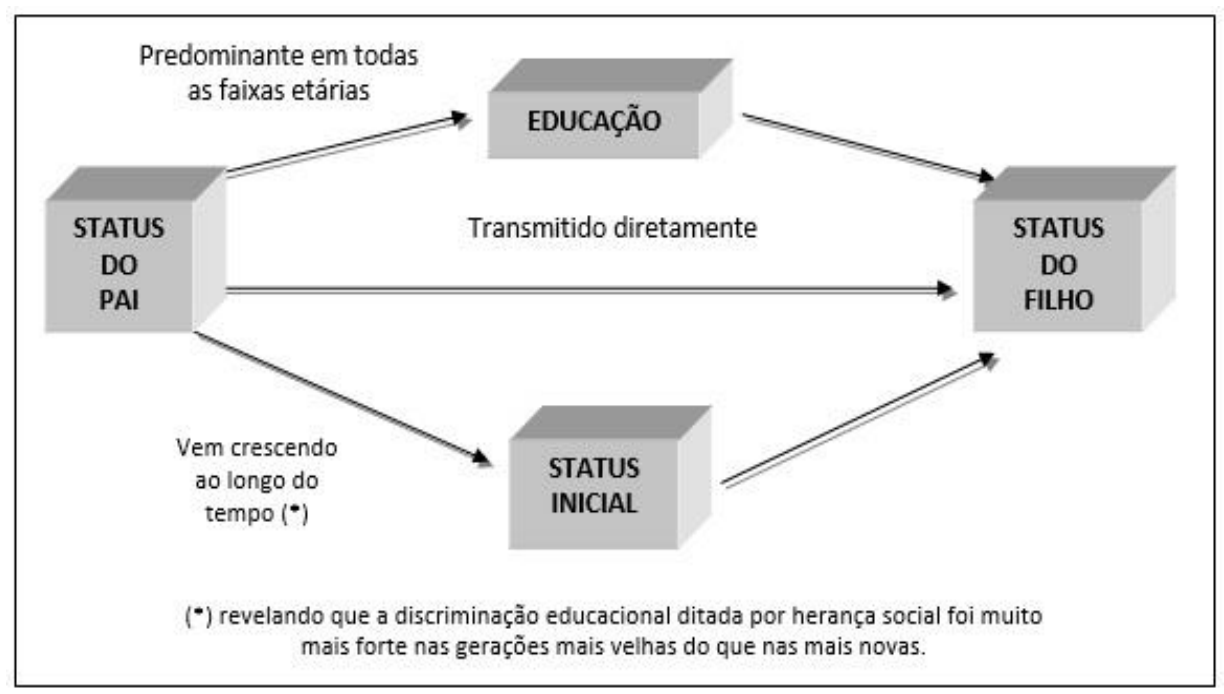

Fonte: A autora, 2015. Elaborada a partir da obra “Desigualdade e mobilidade social no Brasil”, 1979.

Já em relação à análise da rigidez, o autor verificou que esta relaciona-se à crescente e exagerada participação do Estado na economia brasileira, dado que o Estado é o principal responsável pela expansão ou contração do setor privado, assim como pelo incentivo em relação à geração de novos postos de trabalho, redirecionando às macropolíticas governamentais.

Seus estudos permitiram identificar ainda, em que nível da pirâmide social a permeabilidade é maior.

Figura - 3: Determinantes da mobilidade social 


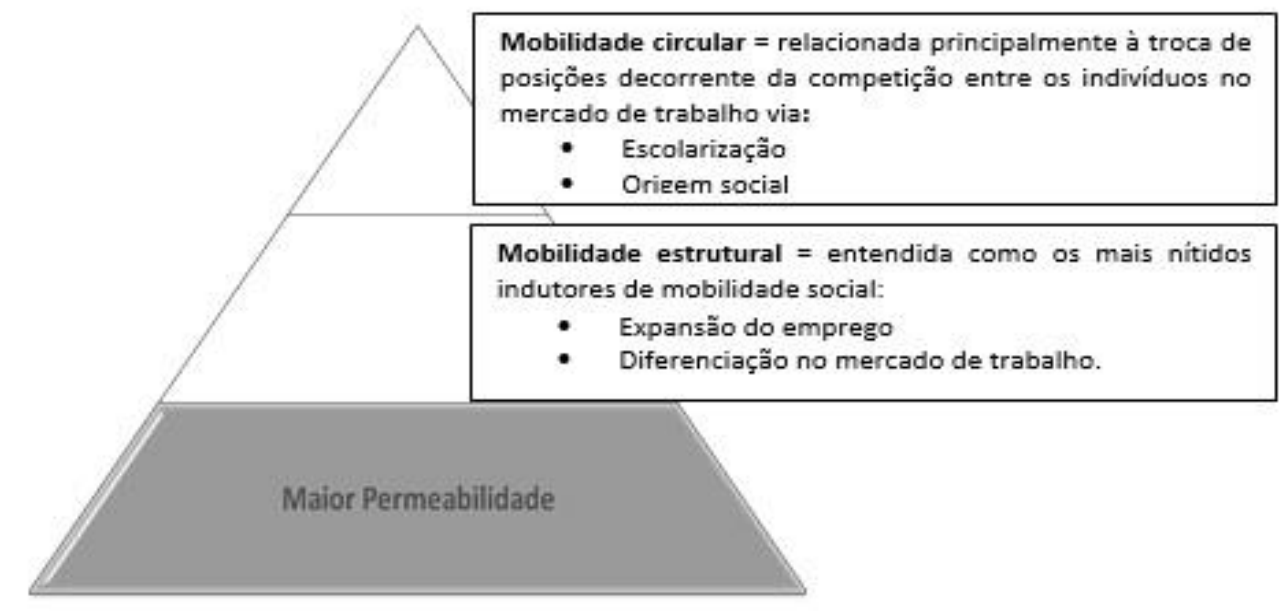

Fonte: A autora, 2015. Elaborada a partir da obra "Desigualdade e mobilidade social no Brasil", 1979.

Por fim, os dados indicaram que quase todos os brasileiros subiram na estrutura de status ocupacionais quando comparados a seus pais, revelando que, a mobilidade social foi abrangente ao longo de toda estrutura social. No entanto verificou-se também que os indivíduos de status baixo percorreram pequenas distâncias sociais, enquanto que indivíduos de status médio percorreram distâncias sociais enormes. Isso revela que há um estiramento das estruturas sociais, de modo que a mobilidade está sempre acompanhada da desigualdade social.

Neste sentido, a pesquisa revelou um paradoxo em relação à mobilidade e desigualdade social no Brasil, posto que, ainda que bastante dinâmica, a sociedade brasileira apresenta uma elevada taxa de desigualdade e seu dinamismo é um fator preponderante para conduzir a sociedade para uma crescente desigualdade social. A mobilidade social no Brasil, portanto, não representa necessariamente igualdade social.

\section{Considerações Finais}

A análise dos dados obtidos resultante da aplicação deste survey permitiu a compreensão quantitativa e qualitativa acerca dos bolsões de pobreza no Brasil, revelando que a despeito de toda a mobilidade registrada, tanto para a população urbana quanto para a rural, as consequências das desigualdades geradas demandam modificações estruturais específicas.

A pesquisa revelou um importante paradoxo acerca do dinamismo estrutural da sociedade brasileira, uma vez que, ao invés de promover a diminuição das diferenças, tal 
dinamismo seria o responsável pela geração de mais e mais desigualdades sociais, tanto para a população urbana quanto para a população rural. Por esse motivo, Pastore afirma que uma possível solução mediante este paradoxo seria a conjugação de três fatores: a inserção e permanência das crianças na escola, sobretudo as das zonas rurais; a diversificação das oportunidades de emprego para os homens (chefes de família) e a formalização do mercado de trabalho para a mulher. Apenas a conjunção desses três fatores resultaria em uma equalização social mais duradoura.

Assim, o estudo desenvolvido por este autor acerca da estrutura social brasileira e o processo de estratificação que a envolve, constitui-se em um primoroso exemplo de aplicação desta metodologia para os futuros pesquisadores da área, especialmente quando se pretende compreender fenômenos que englobam um contingente populacional muito denso e um período de tempo e espaço muito amplos. Por esse motivo, tal obra tornou-se referência obrigatória nos cursos de graduação e pós-graduação de todo o país.

\section{Referências}

BABBIE, Earl. Métodos de Pesquisas de Survey. Tradução de Guilherme Cezarino. Belo Horizonte: Editora UFMG, 2001.

PASTORE, José. Desigualdade e mobilidade social no Brasil. São Paulo: T.A Queiróz Editor, 1979.

Recebido em: 15/07/2015.

Aceito em: 15/01/2016. 